\section{Forensic odontology, part 3. The Australian bushfires - Victoria state, February 2009}

\author{
J. Hinchliffe ${ }^{1}$
}

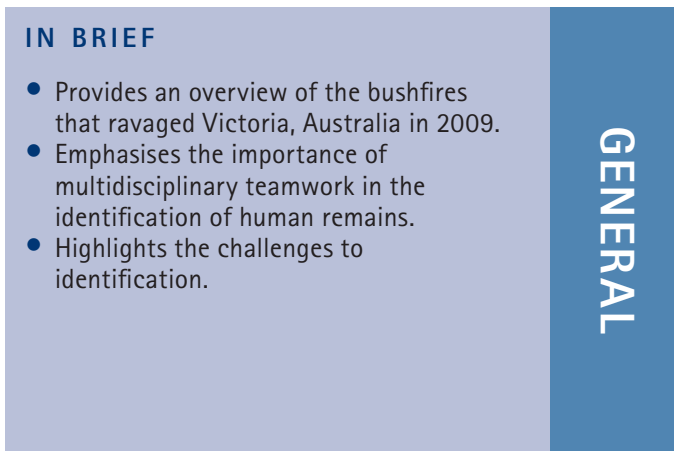

\begin{abstract}
This paper aims to demonstrate the stages in the disaster victim identification of those who lost their lives in the Australian bushfires that raged across the state of Victoria in February 2009. Communities were damaged or destroyed leaving families distressed and homeless, and as the number of deaths increased the Disaster Victim Identification (DVI) teams were activated, with plans evolving to deal with this emergency. The identification process was challenging due to many factors, such as the dangers and difficulties involved in body recovery and the charring and commingling of remains. It would take several months of careful work to identify the dead using a multidisciplinary approach. The impact of this incident will have long-lasting consequences for the families and communities involved. At the time of writing all but one of the 173 victims had been identified, mostly by dental methods: quite remarkable when only small fragments of the dental structures remained in many cases. This article is based on the author's personal experience working to assist the organised and experienced Australian Dental DVI Team.
\end{abstract}

\section{INTRODUCTION}

Bushfires are a common occurrence during the long hot summer months in Australia, and those who live in vulnerable areas are aware of the associated risks. In general, bushfires are well understood and authorities are able to act quickly and effectively to contain and control them, with minimal loss of life and structural damage. However, the fires that swept across the state of Victoria in February 2009 will change the perceptions and approach to fire safety preparations in the future. The horror, loss of life and impact on these communities will be felt for many years to come.

The 2009 fires caused the highest ever loss of life from bushfires in Victoria and the whole of Australia (Table 1). In total 173 people died and it is estimated that over 400 people were injured, with over 2,000 homes destroyed (Fig. 1), leaving thousands homeless and relying on temporary accommodation in caravans,

${ }^{1}$ Forensic Odontologist, New Zealand Correspondence to: Dr Judy Hinchliffe Email: judy.hinchliffe@gmail.com

\section{Refereed Paper}

Accepted 15 December 2010

DOI: $10.1038 /$ sj.bdj.2011.239

${ }^{\circ}$ British Dental Journal 2011; 210: 317-321

\begin{tabular}{|c|c|}
\hline Date & Number of deaths \\
\hline Feb 7-March 2009 - Black Saturday Fires & 173 \\
\hline 16 February 1983 - Ash Wednesday Fires & 47 (total 75, but 28 deaths elsewhere) \\
\hline December-January (13) 1939 - Black Friday Fires & 71 \\
\hline February-March 1926 & 60 \\
\hline 1943-1944 & 51 \\
\hline 8 January 1969 & 23 \\
\hline 14-16 January 1962 & 14 (approximately - numbers reported vary) \\
\hline 1 February 1898 - Red Tuesday Fires & 12 \\
\hline 6 February 1851 - Black Thursday Fires & 12 (approximate number) \\
\hline January 1965 & 10 \\
\hline February 1977 & 8 \\
\hline 2 December 1998 & 5 (volunteer firefighters) \\
\hline 21 January 1997 & 3 \\
\hline
\end{tabular}

tents, beds in community relief centres, and friends' spare rooms. Most of the victims were local residents, but a few foreign nationals also lost their lives. Many towns and small communities north-east of Melbourne were damaged or almost completely destroyed, including Kinglake (population of approximately 1,500), Marysville (population of approximately 500), Strathewen (population around 200),
Flowerdale, Narbethong, and many others. The surrounding land is mainly farmland, National Parks/Forest Reserves, and much of this was reduced to ash (Fig. 2).

\section{PREVAILING CONDITIONS}

By the morning of Saturday 7 February, a total fire ban was in place. Humidity was very low, around 6\% (the average humidity on a summer day in Melbourne is 43\%). 
Melbourne recorded a maximum temperature of $46.4^{\circ} \mathrm{C}$, the highest in the city since records began. High wind speeds in excess of $120 \mathrm{~km} / \mathrm{h}$ and a tinder dry state along with a high fuel load (trees, bushes, grass) in a drought area meant that conditions were building towards the inevitable outbreak of fire.

The McArthur Forest Fire Danger Index (FFDI) is used in Australia in an attempt to assess the likelihood and severity of bushfires. A high index (of around 100) indicates that fires will be almost impossible to control. That weekend the FFDI reached unbelievable levels, ranging from 120 to over 200. Disaster was imminent.

\section{EVENTS LEADING TO DISASTER}

In early February 2009 the temperature had been consistently high for many days and fires had been reported and mostly contained by fire crews. However, the fire at Bunyip State Park broke through containment lines and into surrounding land and villages during the extreme conditions of February 7.

By late morning on February 7 wind speeds reached their peak (up to $130 \mathrm{~km} / \mathrm{h}$ ), bringing down power lines in Kilmore East and sparking a bushfire that would develop into the largest and deadliest that Victoria had ever experienced. The fire soon took hold, fuelled by woodland plantations. Bark released from burning trees and carried by the wind started fires elsewhere up to $15 \mathrm{~km}$ ahead of the fire front. It is reported that the fire travelled $60 \mathrm{~km}$ in a couple of hours. Barriers such as roads or lakes that would normally have prevented the spread of fire were rendered useless by the strength of the wind blowing fireballs across them.

By 14:00 hours that day the State Emergency Control Centre received over 1,400 calls reporting fires: some small, some large. Later that afternoon the Murrindindi Mill fire developed, adding another raging fire front. The sun was blocked by smoke and skies darkened. Survivors and fire crews told of the deafening roaring from the fire and wind. Fire crews did what they could but were eventually driven back by flames up to $50 \mathrm{~m}$ in height, the radiant heat, and the sheer scale of the impending disaster: experts suggest that the fires may have been burning at temperatures of $1,200^{\circ} \mathrm{C}$. The fires were beyond control.

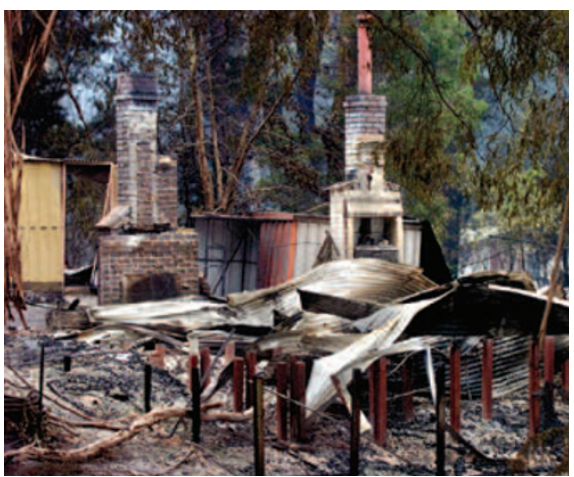

Fig. 1 A home in ruins (photograph with permission - Rob Carew)

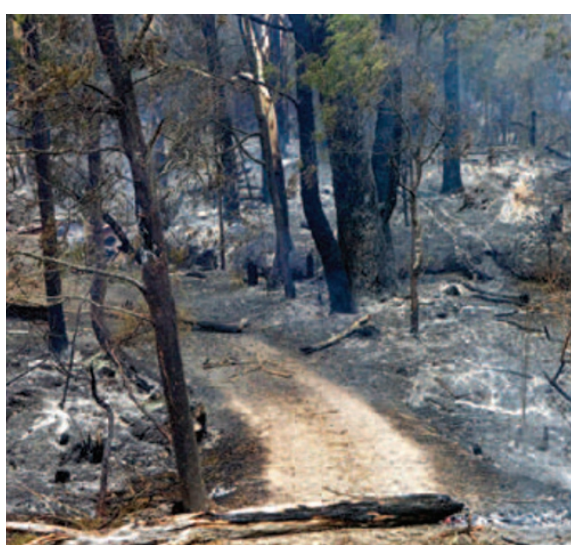

Fig. 2 Woodland reduced to ash (photograph with permission - Rob Carew)

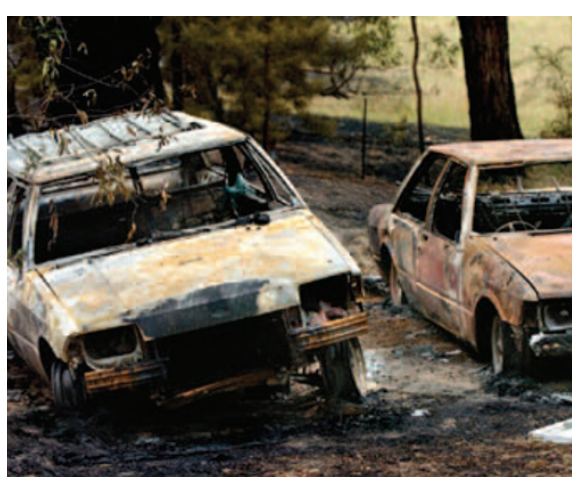

Fig. 3 Fire damaged cars - some would contain the incinerated remains of fleeing residents (photograph with permission - Rob Carew)

Later in the day a change of wind direction threatened areas previously thought to be safe: residents panicked, some trying to escape in cars only to find the roads blocked by fallen and burning trees, or crashing because visibility was reduced by the thick smoke (Fig. 3). How to escape? Whatever fire preparations homeowners had made would not be enough to protect many of the families sheltering in their homes or buildings in the townships.

Stay and defend your home (if it is defendable) or get out fast had been the policy that had worked well in the past, but now

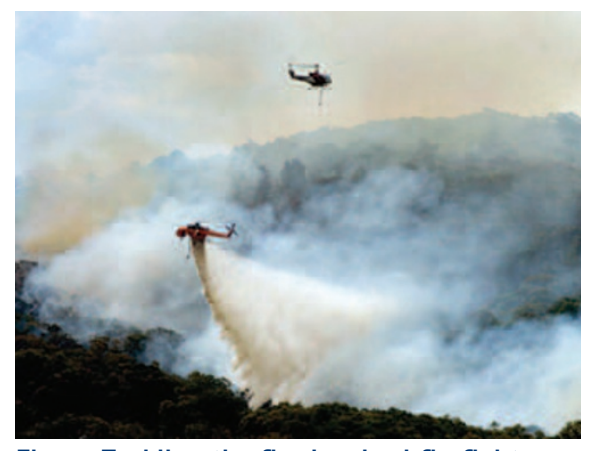

Fig. 4 Tackling the fire involved firefighters, military and air teams (photograph with permission - Rob Carew)

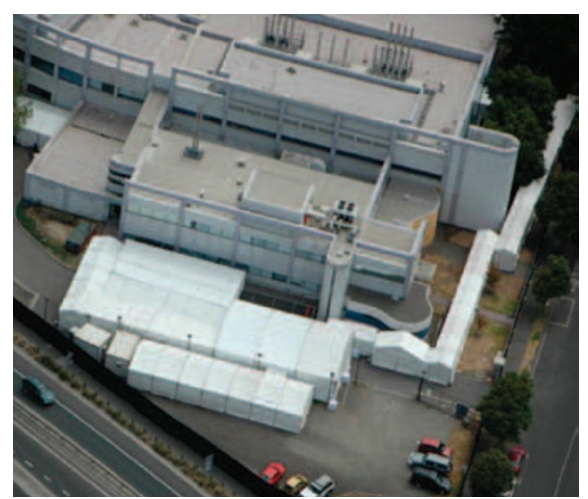

Fig. 5 Victorian Institute of Forensic Medicine and Coronial Services temporary mortuary facility, showing marquees and security fencing in place and refrigerated containers (photograph with permission - VIFM)

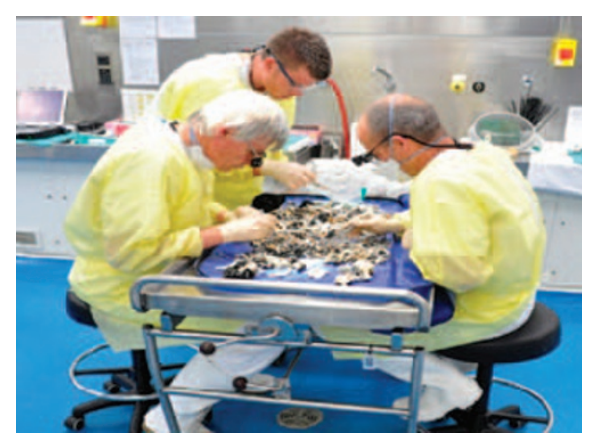

Fig. 6 Forensic odontologists search for dental structures (photograph with permission - VIFM)

it was a life or death decision for many at a time when power and phone lines had been cut off by fire, leaving little or no means of communicating with the outside world. One elderly gentleman, whose property was one of three not destroyed by fire for miles around, explained that it was essential (and common sense in high risk areas) to keep grass down, clear rubbish and have no trees near the house: 'no fuel, no fire.' However, Victorian Premier John Brumby said 'There were many people who had done all of the preparations, had the best fire plans in the world and tragically it didn't save them.' 
On the evening of February 7, Melbourne hospitals were notified by the Victorian Health Emergency Coordination Centre to be prepared for burn victims. St John's Ambulance sent staff to assist and volunteers offered to help.

Merging of some of the fires the following day caused further death and destruction, although it is believed that most fatalities occurred between 18:00 hours and 21:00 hours on Saturday 7 February, now known as 'Black Saturday'. Fires burned for several weeks: old ones reigniting and new fires starting, with smouldering areas lingering for many weeks across six separate regions.

Several weeks later, roadblocks were still in place in many towns and hamlets to prevent the sightseeing general public and looters from accessing the towns; disasters such as this bring out the best and worst of the human race. Residents along with their families and friends were able to look through the remains of their homes (once all risks had been removed) and salvage what they could find. Some homes were spared against all the odds: an unaffected home surrounded by destruction. It will take a long time for normality to return and I wonder how I would feel returning to my home if I had lost family and friends or long-term neighbours, and my view was of burned trees, hills and buildings?

\section{RESPONSE AND POSSIBLE CAUSES}

Firefighters from the Country Fire Authority (CFA), the Department of Sustainability and Environment (DSE), and assisted by the military and water-dropping aircraft (Fig. 4) worked together in an attempt to contain the fires. Over 4,000 firefighters took part. In response to the escalating fires, New Zealand, along with other Australian states, sent firefighting personnel, but numbers from New Zealand were limited because of the extreme fire risk in parts of their own country at the same time. Sadly, a firefighter (assisting from Canberra) lost his life when a burnt tree branch collapsed onto his fire tanker.

Various factors were implicated in the initial fire ignition, including lightning (which can be caused by violent forest fires which generate sufficient dust to create a static charge), sparks from damaged power lines, cigarette butts, sparks from a power tool and arson. It is hard to believe that someone would deliberately start a fire, but the Commissioner of the Victoria Police stated that all fire sites would be treated as crime scenes because of the suspicion of arson one Churchill resident was charged with arson on February 13 2009. This would be the largest police investigation undertaken in Victoria, to include 3,000 statements.

\section{THE FIRST 24 HOURS}

With the number of deaths rising, the Victorian State Coroner held meetings with various agencies including the police, Disaster Victim Identification (DVI) coordinators, forensic science personnel and the media. It is important to put plans in motion, agree protocols and assemble teams rapidly to deal effectively and sensitively with such incidents. Teamwork, cooperation and communication is essential along with the ability to adapt to the developing situation. As the number of fatalities increased, there was a corresponding increase in pressure on the teams from families and the media anxious for news and progress.

\section{THE SCENES}

All the fire sites were visited with tight security to locate and collect human remains and arrange transport to the temporary mortuary; over 4,000 properties were searched. The injured were taken to hospital and the homeless were offered temporary accommodation.

The recovery of human remains and the identification process started as soon as possible with the arrival of the DVI teams. Remains were photographed in situ and given a DVI number, the site marked with a corresponding number, and then the remains were carefully bagged for transfer to the mortuary. Skulls and dental structures were bubble-wrapped and placed in plastic bags to protect the potentially valuable dental evidence from further destruction. Easily recognisable remains were moved first, but it would take several scene visits to locate charred remains among the ash and rubble. Searches were hindered by the dangerous conditions. Ideally, in situations such as this, it is useful for pathologists, anthropologists and forensic odontologists to attend the scene to assist with the identification and recovery of human remains, but with so many sites this was not considered practical.

\section{Scene problems}

- Open disaster

- Multiple sites separated by large distances

- Movement of people during and around the incident time

- Dangerous structures

- Asbestos present in some buildings - protective clothing and equipment needed

- Some sites still burning/smouldering during the searches and investigation

- Limited experience of some recovery teams

- Road access - for example blocked by debris, burning trees and/or crashed cars

- Presence of non-human remains

- Commingling of remains

- Remains reduced to ash.

\section{THE MORTUARY}

A temporary mortuary was established within two days at the Victorian Institute of Forensic Medicine (Fig. 5) which adjoins the Coronial Services Centre at Southbank, Melbourne. Security was put in place and screening placed around the complex perimeter to ensure privacy. Extra pathologists were called upon to take care of the day to day work as this was a busy mortuary already coping with the extra demands of frail people dying in the heat wave.

The remains were stored in refrigerated containers at the mortuary site. The autopsies were limited to identification issues following discussion with the coroner. The remains were given a barcode, photographed, and had CT scans which proved extremely useful, assisting with age and gender information, the detection of metallic devices and providing good images of dental structures. Any associated personal effects were also numbered, photographed, cleaned and securely stored. The remains were then examined by forensic specialists and DNA samples were taken where possible. Unfortunately some of the remains were incinerated or badly charred, but small fragments of the dental structures were found in many cases (Fig. 6). Dental fragments were examined, photographed and radiographs were taken using portable, hand-held machines and digital sensors.

All data relating to the postmortem findings were noted on pink DVI forms and entered onto the computer system (Plass 
Data). Dental information was entered by forensic odontologists.

\section{Mortuary problems}

- Continuity of evidence - shift work of teams may lead to lack of continuity

- Different experience levels of team members

- Familiarisation with equipment, eg digital radiography equipment and Plass Data. Rapid on the spot training is not satisfactory

- Dental resection of jaws or not? None were resected in this disaster.

\section{ANTEMORTEM INFORMATION COLLECTION}

Meanwhile, over 100 detectives (working in pairs and accompanied by a counsellor), approached surviving family members to obtain antemortem information relating to the potentially deceased person, including information on dental surgery attendance and the whereabouts of any dental records. All missing persons were given an antemortem number and all antemortem information was entered into Plass Data from the yellow DVI forms, the dental sections being completed and entered by forensic odontologists. Antemortem dental radiographs were scanned into digital format.

The forensic dental team members were largely selected because of their experience in this field of work and their association with the Australian Society of Forensic Odontology. In total, 56 dental personnel were involved at one time or another with the response, including five forensic dentists form New Zealand, three from Indonesia and observers from Japan. I assisted as a wandering NZ/UK forensic dentist but only in the later stages in March.

\section{IDENTIFICATIONS AND THE IDENTIFICATION BOARD}

Whenever there is loss of life, and particularly on this scale, there is pressure on the identification teams from the community and the media to give rapid results. However, mistakes are unacceptable and cause much extra distress, so the process must be done carefully (all stages are quality assured) and it is often painfully slow. It is important to explain delays to relatives and keep communications open to avoid further anxiety or anger.
Each different DVI section (eg odontology, fingerprint, anthropology, pathology, personal effects, and police) tries to match antemortem information with postmortem findings. It may be that a positive identification can be made using teeth supported by personal effects and location where the remains were found, along with witness statements. Identifications from DNA may take a little longer, depending on the laboratory facilities and capabilities.

The teams worked together to identify charred remains and present information to the Identification Board, headed by the State and Deputy State Coroners. All evidence for a positive identification would be put before the coroners, so that they were satisfied that the required standard of proof of identity was established (with no unexplainable inconsistencies). Dental evidence was presented using PowerPoint, showing antemortem (when available) and postmortem radiographs (Figs 7a and 7b) to support oral and written evidence. Witness statements often revealed sad and harrowing insights into the deaths, for example a son watching his father trapped in his truck being engulfed in flames.

The proceedings were recorded, with a different tape for each case; the tape was then kept with the case file as part of the record. All cases were completed in accordance with the Certificate of Identification Form created for this incident. On 7 May 2009, exactly three months after the beginning of the firestorm, the final Coroner's Identification Board was held. Of the 173 people who lost their lives, 172 were positively identified (nine of the deceased did not pass through the DVI procedure because they died at a later date as a consequence of the disaster). Approximately 300 DVI cases were created - partial and incomplete remains increasing the numbers. All remains were examined and reported upon: many cases were commingled remains and an endeavour was made in all cases to re-associate the body parts with known remains. On examination some remains were found to be non-human. Once identification had been established the families could be notified and the remains released and collected by the funeral directors.

Some of the remains could not be reassociated with a victim and were buried separately. All inquests were concluded

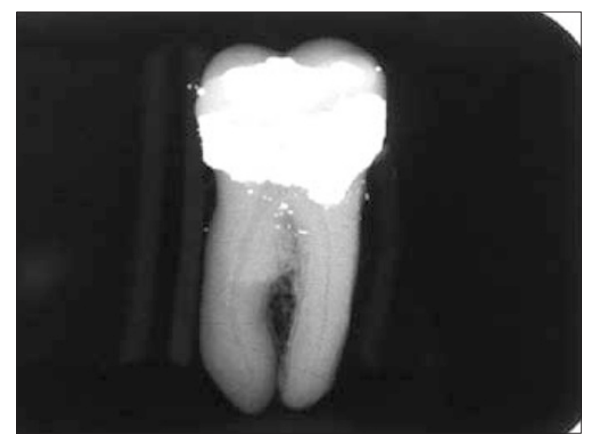

Fig. 7a Postmortem radiograph for comparison with Figure $7 \mathrm{~b}$

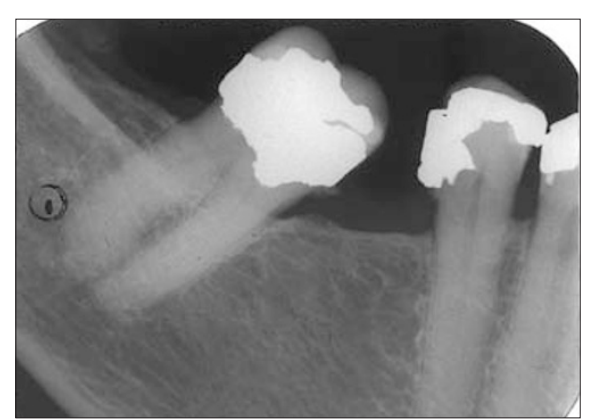

Fig. 7b Antemortem radiograph taken in 1997

when the Royal Commission finished its investigations.

\section{Some statistics}

- Fires affected 78 individual towns

- 760 vehicles were destroyed

- 100 males and 73 females lost their lives

- Most deaths occurred in the Kinglake and Marysville areas.

According to Wikipedia, most deaths were accounted for as follows:

- Seven deaths occurred in bunkers

- 113 were discovered inside buildings

- 27 were discovered outside houses

- 11 were found in vehicles

- Six were found in garages

- Five were found near vehicles

- One was found on a reserve

- One was found in a shed.

\section{THE FUTURE}

Debriefing at all levels followed this incident, enabling the strengths and weaknesses of the response to be addressed and acted upon for future emergencies. The Australian Dental DVI team is well organised, with robust protocols and guidelines that contributed to the success of this operation.

As a direct result of this disaster and the number of fatalities, policies for dealing 
with such fires will be evaluated, along with the emotional, economic and environmental impact. Premier John Brumby announced that there would be a Royal Commission to examine all aspects of the government's bushfire strategy along with the role that climate change may have played in the severity of the fires. At the time of the fires, Victoria had no separate building code for properties in areas susceptible to bushfires, and the Royal Commission will be looking to make recommendations for future building regulations and standards.

\section{CONCLUSIONS}

Disasters will continue to claim lives and cause distress. Since the events of February 2009 there have been many more incidents around the world, such as the major earthquakes in Haiti and Christchurch, earthquakes and tsunamis in Samoa and Japan, typhoons in the Philippines, air, rail and road incidents, wars and terrorist attacks. The most effective way of dealing with these situations (if they cannot be prevented) is to be prepared, with trained teams in place to assist at short notice.

It is always a humbling experience to work in such situations, keenly aware of the human suffering but hopefully able to assist in some small way. In this particular disaster it is remarkable that dentistry made such a positive impact on the identifications, despite the condition of some of the remains: a true reflection of the resilience of the dental structures and the importance of accurate and comprehensive antemortem dental records. Over $60 \%$ of the identifications had dental input and 40\% were based on dentistry alone.

The land is already recovering, and may even flourish; properties will be rebuilt and life will go on, but these fires will have had devastating consequences for many families and will forever change their lives.

The author wishes to thank The Victorian Institute of Forensic Medicine/Coronial Service, Tony Hill and Richard Bassed (both forensic odontologists from Melbourne and colleagues that she has had the pleasure of working with on previous disasters) for providing assistance and sharing information for this article; Jane Taylor for her hard work developing the comprehensive 'Australian Forensic Odontology Disaster Victim Identification Practice Guidelines', upon which the successful dental response was based; and Rob Carew, a photographer from Melbourne, who greatly assisted by generously giving his permission to use some of his photographs. 